\title{
EVERYDAY LIFE INJURIES AMONG CHILDREN UNDER 6 YEARS OLD: ACCIDENT OR NEGLECT ?
}

\author{
Toualouth Lafia 1, 2,5*, Loubna Aqqaoui 1,2,3, Fouad Ettayebi 1,2, and Houda Oubejja 1,2,3,4 \\ 1-Department of pediatric surgical emergencies, children's hospital of Rabat, Morocco. \\ 2-Faculty of medecine and pharmacy, University Mohammed V, Rabat, Morocco. \\ 3-Laboratory of Genetic and Biometry, faculty of science, university Ibn Tofail Kenitra, Morocco. \\ 4-Laboratory of epidemiology, clinical research and Biostatistics, faculty of medecine and pharmacy, University Mohammed V, Rabat. \\ 5-Ministry of health, Republic of Benin.
}

\begin{abstract}
Injuries related to everyday accidents are very common in children and are the main reasons for hospitalization in pediatric surgery. They have similarities with neglect. The main objective is to assess the frequency and circumstances of the occurrence of unintentional accidents in children under 6 years old. The secondary objective is to specify the associated factors and eventually determine if those accidents can be related to neglect. Material and methods: This is a cross-sectional study carried out at Pediatric Surgical Emergencies Department of Rabat Children's Hospital in 2017. Results: We identified 363 cases of unintentional accidents. The variables were collected on questionnaire. 155 children were aged 6 and under. The median age was 2,83 years with a predominance of boys $(56 \%)$. Children over 2 years old were the most affected $(55.48 \%)$. Low and middle-income families dominated socio-demographic factors. The mothers in almost half of the cases never went to school. In $65.4 \%$ of cases, an adult was present during the accident, often the mother (62\%). The lesions involved the limbs (64\%) and the head (47\%). Hospitalization was 24 hours $(60.8 \%)$. There was no complication in $96.8 \%$ of cases. Some risk factors associated with unintentional accidents are also found in negligence.
\end{abstract}

Key words: unintentional- accident-children- hospitalization-Morocco

\section{Introduction}

Unintentional accidents include road traffic accidents, work accidents and "everyday accidents". Those "everyday accidents" are defined as accidents occurring in or near the home, during sport or at recreation areas, and at school.

According to The World Health Organization (WHO), 950000 adolescents under 18 years old died every year because of traumas and accidents. 830000 deaths $(90 \%)$ are classified as "unintentional" [1]. In France, unintentional injuries cause around 40,000 deaths each year, including 21,000 deaths from everyday accidents and several million emergency calls [2]. In Tunisia, domestic accidents alone represent $3.25 \%$ of the hospital incidence of the Tunis Children's Hospital with predominance among children less than 3 years old [12]. Those accidents may occur because of maltreatment or neglect. Neglect is defined as "including both isolated incidents, as well as a pattern of failure over time on the part of a parent or other family member to provide for the development and well-being of the child in one or more of the following areas: health, education, nutrition, shelter and safe living conditions [3].

There are several factors that contribute to neglect. Those factors can be involved in unintentional accidents. According to the results of the meta-analysis carried out by Stith et al [4], the risk factors associated with child neglect can be classified into 4 types:

- Interaction between the parent and his child (perception that the parent has of his child's behaviour, corporal punishment, etc.)

- Characteristics specific to the parent (drug addiction, alcohol, illness, etc.)

- Characteristics specific to the child (sex, behaviour, sick, adopted child, etc.)

- Family factors (socio-economic level, number of children, etc.)

The aim of this study is:

*Corresponding author: toual26@yahoo.fr 
- To assess the frequency and circumstances of the occurrence of unintentional accidents in children under 6 years of age, and specify the associated factors.

- To eventually determine how those accidents can be considered as neglect.

\section{Material and Methods}

This work is a cross-sectional study carried out in the Paediatric Surgical Emergencies (PSE) Department of Children's Hospital of Rabat, over a period of one year (2017). Cases of everyday accidents in children under 16 have been identified. We excluded from this study, cases of drowning and inhalation of foreign bodies (because they were taken care of in another department). We used a questionnaire (annex 1) filled in by the physician receiving the children in the surgical emergency and completed if necessary after a phone call.

We then selected for analysis, the data of children under 6 years. The socio-demographic variables (age, sex, schooling status, parent and family information, housing), clinical and radiological characteristics were analysed as well as the information about the accident. We have divided the population into 2 groups: children under 2 years old group (infants) and 2-6 years group (preschool).

The data collected was analysed using Jamovi 1.6.23 software. We used the chi-square test to compare the two groups.

\section{Results}

During the period, we collected data of 363 pediatric patients of whom 155 cases were selected (patients under 6 years old). The median age was 2.83 years [1.08; 5]. The population under 2 years old included 69 children (44.52\%) against $86(55.48 \%)$ for those over 2 years old. The socio-demographic characteristics and those specific to the accident have been presented in table 1 and 2 .

The distribution by gender has been explained in figure 1 . There were 87 boys and 68 girls.

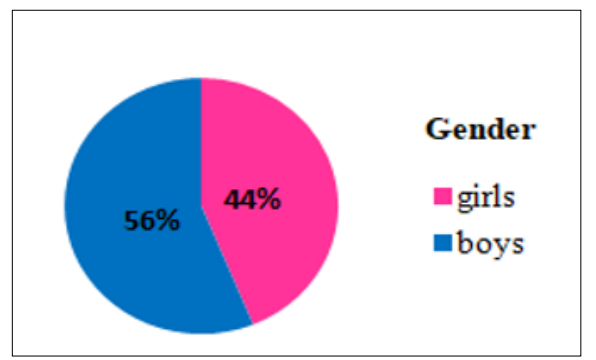

Figure 1: gender distribution of patients presenting unintentional accident under 6 years old, paediatric surgical emergencies, Children's hospital of Rabat, 2017.
Table 1: Socio-demographic characteristics of patients presenting unintentional accident under 6 years old, paediatric surgical emergencies, Children's hospital of Rabat, 2017.

\begin{tabular}{|c|c|c|}
\hline \multicolumn{3}{|c|}{ Schooling } \\
\hline \multicolumn{2}{|l|}{ yes } & $35(22.6)$ \\
\hline no & & $120(77.4)$ \\
\hline \multicolumn{3}{|c|}{ Living environment } \\
\hline \multicolumn{2}{|l|}{ Urban } & 127 (81.9) \\
\hline \multicolumn{3}{|l|}{ Income } \\
\hline \multicolumn{2}{|l|}{ Medium } & $64(42.4)$ \\
\hline \multicolumn{2}{|l|}{ High } & $4(2.6)$ \\
\hline \multicolumn{3}{|c|}{ Family size } \\
\hline \multicolumn{2}{|c|}{$>4$ children } & $19(12.25)$ \\
\hline \multicolumn{3}{|c|}{ Parents educational level } \\
\hline \multirow[t]{4}{*}{ Father } & Unschooled & $48(31.8)$ \\
\hline & Primary & $26(17.2)$ \\
\hline & Secondary & $54(35.8)$ \\
\hline & University & $23(15.2)$ \\
\hline \multirow[t]{4}{*}{ Mother } & Unschooled & $70(45.8)$ \\
\hline & Primary & $24(15.7)$ \\
\hline & Secondary & $44(28.8)$ \\
\hline & University & $15(9.8)$ \\
\hline
\end{tabular}

RAMED $=$ Medical Assistance Regime; AMO = Mandatory Health Insurance; low: <3000 MADs, medium: 3000- 10000 MADs, high : $>10000$ MADs (MADS= Dirhams); n (\%)

The majority of child victims of accidents were under the tutelage of their two parents (79\%). Single-parent families corresponded to $18 \%$ of the population and in $3 \%$ of cases the child was raised by someone else other than his parents. (Figure 2)

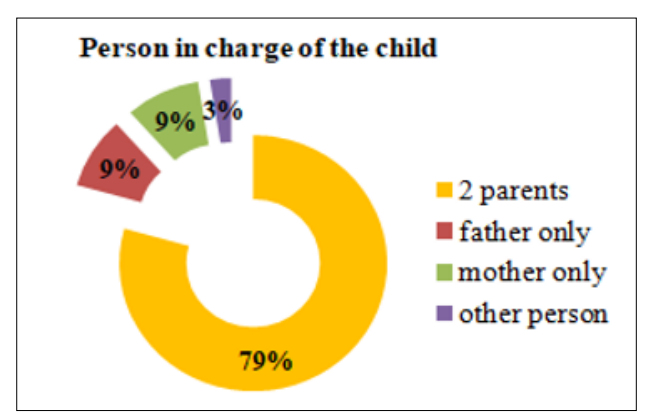

Figure 2: Distribution according to the person in charge of the child, paediatric surgical emergencies, Children's hospital of Rabat, 2017.

Table 2 represents all the data related to the unintentional trauma. 
Table 2: Unintentional trauma characteristics of children under 6 years old, paediatric surgical emergencies, Children's hospital of Rabat, 2017.

\begin{tabular}{cc}
\hline Place of accident & $\mathbf{n}(\mathbf{\%})$ \\
Home & $120(77.9)$ \\
Outside & $35(22.1)$ \\
Circumstances & $\mathbf{n}(\mathbf{\%})$ \\
Fall & $127(81.9)$ \\
Burn & $16(10.3)$ \\
Collision & $12(7.7)$ \\
Hospitalization & $\mathbf{n}(\mathbf{\%})$ \\
Yes & $129(83.2)$ \\
No & $26(16.8)$ \\
Place of hospitalization & $\mathbf{n}(\%)$ \\
PSE department & $125(96.9)$ \\
ICU & $4(3.1)$ \\
Outcome & $\mathbf{n}(\%)$ \\
No complications & $142(94.7)$ \\
Complication & $5(3.2)$ \\
\hline
\end{tabular}

In most cases, an adult was present during the trauma (figure 3 ) in $65 \%$ of cases.

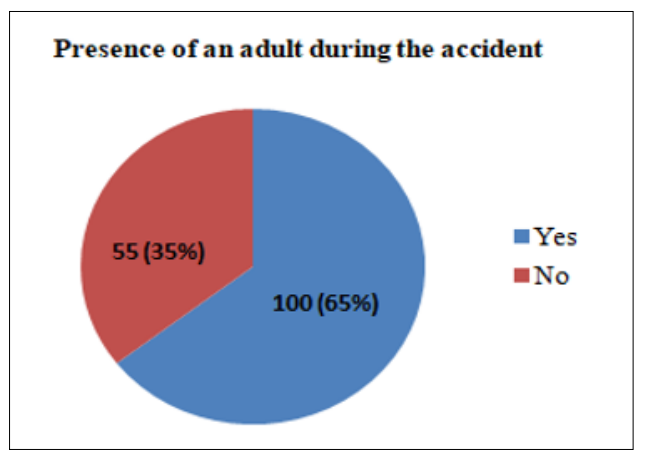

Figure 3: distribution according to the presence of an adult during the accident, Children's hospital of Rabat, 2017.

More specifically, this number was higher for the children under 2 years of age than for those aged 2-6 years (Table 3 ).

Table 3: Presence of an adult at the moment of accident depending on the age groups, paediatric surgical emergencies, Children's hospital of Rabat, 2017.

\begin{tabular}{|c|c|c|c|}
\hline & \multicolumn{2}{|c|}{$\begin{array}{c}\text { Presence of an adult } \\
\qquad \mathrm{n}(\%)\end{array}$} & p \\
\hline $\begin{array}{c}\text { Age } \\
\text { Groups }\end{array}$ & No & Yes & $<0.001$ \\
\hline$<2$ years & $14(20.6)$ & $54(79.4)$ & \\
\hline 2-6 years & 39 (45.9) & $46(54.1)$ & \\
\hline
\end{tabular}

In $69 \%$ of cases the mother was present at the time of the trauma. The presence of both parents was only found in $3 \%$ of cases while the trauma had occurred in the presence of the father alone, in $9 \%$ of cases. (Figure 4)

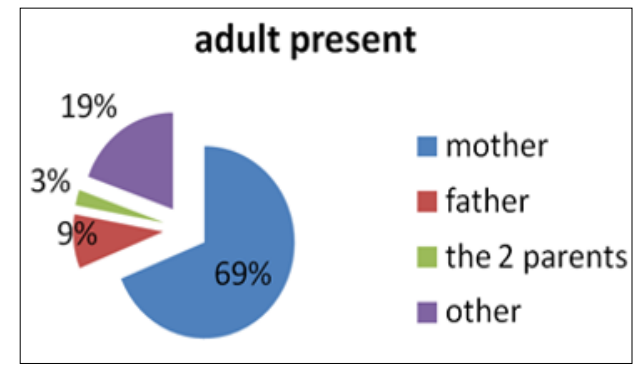

Figure 4: adult present at the time of the accident, paediatric surgical emergencies, Children's hospital of Rabat, 2017.

Regarding the lesions, the parts of the body affected during the accidents were the limbs, and then the head, followed by multiple lesions (Figure 5).

The comparison between age group highlighted the predominance of cephalic lesions in children under 2 years old $(46,4 \%)$ versus $17,6 \%$ in the second group. Meanwhile, limbs were affected in $53 \%$ for children over 2 years old versus $27,5 \%$ for those under 2 years. (Table 4). All these differences are statistically significant.

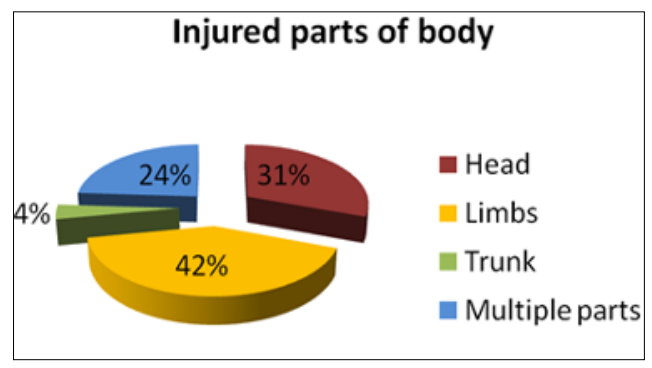

Figure 5: Injured parts of body, children less than 6 years old presenting unintentional accident, paediatric surgical emergencies, Children's hospital of Rabat, 2017.

Table 4: Parts of body injured compared within age group, paediatric surgical emergencies, Children's hospital of Rabat, 2017.

\begin{tabular}{|l|c|c|c|c|}
\hline \multicolumn{3}{|c}{ Body parts injured } & \multicolumn{2}{c|}{$\boldsymbol{p < 0 0 1}$} \\
\hline $\begin{array}{l}\text { Age } \\
\text { Groups }\end{array}$ & $\begin{array}{c}\text { Head } \\
\mathrm{n}(\%)\end{array}$ & $\begin{array}{c}\text { Limbs } \\
\mathrm{n}(\%)\end{array}$ & $\begin{array}{c}\text { Trunk } \\
\mathrm{n}(\%)\end{array}$ & $\begin{array}{c}\text { Multiple } \\
\mathrm{n}(\%)\end{array}$ \\
\hline $\begin{array}{l}<2 \\
\text { years }\end{array}$ & $\begin{array}{c}\mathbf{3 2} \\
\mathbf{( 4 6 . 4 )}\end{array}$ & $\begin{array}{c}19 \\
(27.5)\end{array}$ & $1(1.4)$ & $17(24.6)$ \\
\hline $\begin{array}{l}2-6 \\
\text { years }\end{array}$ & $\begin{array}{c}15 \\
(17.6)\end{array}$ & $\begin{array}{c}\mathbf{4 5} \\
\mathbf{( 5 2 . 9 )}\end{array}$ & $5(5.9)$ & $20(23.5)$ \\
\hline
\end{tabular}

The lesions found were: fractures $(50.7 \%)$, contusions $(27 \%)$, burns $(10.5 \%)$, wounds $(6.6 \%)$ and abrasions $(5.3 \%)$. Figure 6 gives a description of their distribution 


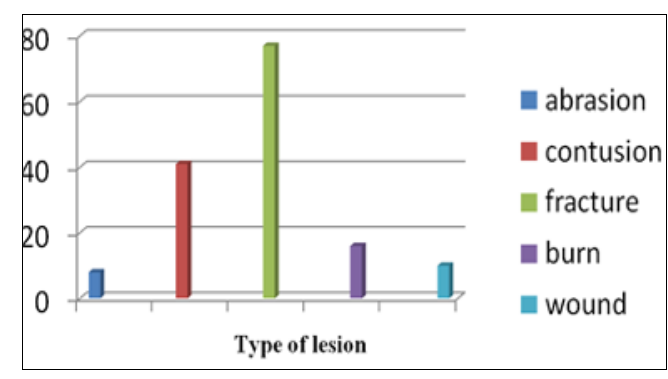

Figure 6: Distribution according to the type of lesion, paediatric surgical emergencies, Children's hospital of Rabat, 2017.

\section{Discussion}

\subsection{What are the characteristics and risk factors associated with everyday accidents in children under 6 ?}

In our study, the median age was 2.83 years $(1.08 ; 5)$. The risk of accident in this category is linked to cognitive development (recognition of the danger), psychomotor immaturity and limited physical capacities (short stature, developing locomotor capacities, etc.). The predominance of children over 2 years $(55.48 \%)$ more than infants $(44.52 \%)$ may be due to the fact that infants benefit from more parental supervision while it is less strict for second age group (acquisition of walking, desire to discover and explore the world...etc). On the other hand, we observed a male predominance $(56.1 \%$ vs $43.9 \%)$. This is explained by the turbulent nature of the boys. In $77.9 \%$ of the cases, those accidents were domestic. When it came to extra-domestic accidents, it happened in play areas (in $69.7 \%$ of cases). The majority of the children $(77.4 \%)$ were not in school and only $2.58 \%$ of the accidents recorded occurred in school. This can be explained by the fact that at school, children would be less exposed (rigor, work environment, strict supervision of teachers, more time to focus on a task).

Most of the children who are victims of unintentional accidents in our study come from low and middleincome families. Studies have shown that the better the socio-economic level, the better the development of the child. Faelker et al [7] observed that children coming from poor families, seen in emergency rooms are almost twice as likely to have an accident as others, regardless of the type of accident. We noted fewer accidents in families with 4 or more children (13.5\%) than in those with fewer children (86.5\%). These results do not agree with those found in the literature [8,9]. In addition, some studies have shown the low risk of accidents occurring for children living with their two parents, unlike those living in single-parent families or foster families $[10,11]$. In our results, on the contrary, $79.4 \%$ of the children lived with their 2 parents. Only $18 \%$ of them were in a single-parent family.

*Corresponding author: toual26@yahoo.fr
Educational level of parents seems to play an important role in the occurrence of accidents of daily living in children. Indeed, a low parental socioeducational level (more specifically maternal) would increase the risk of an accident. In our study $45,8 \%$ of mothers were uneducated. The low level of education is believed to be the source of a lack of information on the risks run by children $[12,13]$. The presence of an adult at the time of the accident does not appear to be a factor preventing accidents from occurring in children whatever the age (table 3 ). In fact, in $64.5 \%$ of cases, an adult was present at the time of the incident. In more than half of the cases, it was the mother.

The most frequent mechanism is fall principally from the height of the child followed by variable height. This is in agreement with the results of literature $[14 ; 15]$. Falls are explained by the fact that these children are in the motor acquisition phase. The other causes are burns and collisions.

Injured parts of the body were generally: limbs and head followed by multiple lesions (Table 4).More specifically, there is much more head damage in children under 2 years old and less damage to the limbs while this trend is reversed in those over 2 years old. This can easily be explained by the immaturity or even the absence of means of balance and especially of protective mechanisms in the event of a fall (constant to absorb the fall by landing on the upper limbs), which are acquired as the child, grows.

The lesions found were: fractures $(50.7 \%)$, wounds (6.6\%) and burns (10\%).

In $83.2 \%$ these lesions required hospitalization for a minimum of 24 hours. This reflects not only the vulnerability of these age groups but also the potential severity of unintentional accidents.

\subsection{These unintentional accidents are they neglect?}

This is a difficult question to answer. There are many aspects to unintentional accidents, similar to those found in negligence.

The risk factors that emerge from this study among children under 6 are age, gender, house, level of education of mothers and socio-economic level of the family.

The risk factors associated with child neglect are very well known. Mulder et al [5] have explicitly detailed 15 risk factors significantly associated with neglect:

- Unmarried parents.

- Violence at home

- Large siblings: 2 children and more.

- Low socioeconomic status.

- Child does not live with his 2 biological parents.

- Behavioural and cognitive problems within the family.

- History of criminal or anti-social behaviour. 
- Parent has mental health problems.

- Low level of education of parents.

- Parent has a history of abuse during his childhood.

- Young age of parents.

- Non-Caucasian child.

- Child has had perinatal problems.

- Child has mental, physical or behavioural difficulties

In our study, the common factors to unintentional accidents and neglect that stand out are: large family, low socio-economic level, low level of parental education.

Is there a part of negligence in these accidents of everyday life? Yes. But are all the accidents of everyday life negligence? Certainly not.

In our context, the most visible form of abuse and for which the practitioner is better prepared is Silvermann Syndrome, for which methods of diagnosis and care are well codified.

The task is more difficult when it comes to neglect which is also a form of abuse. And for which, training of the different actors involved in the care of children must be done.

Our work does not fully answer the question, but is a preliminary draft for a future work that we will do in order to answer this question more clearly. This will obviously involve raising the awareness of nursing staff and developing tools better suited to the search for risk factors for neglect.

\section{Conclusion}

Risk factors associated to unintentional accidents in children less than 6 years in our study are: age, gender, house, level of education of mothers and socio-economic level of the family. These are also risk factor involved in neglect.

Unintentional accidents may occur sometimes because of neglect. The attempts to respond to this problem will be the subject of a more precise study

\section{References}

[1]WHO 2008, Global Distribution of Childhood Injury Deaths, by Cause, 0-17 Years, World, (2004 update)

[2] https://www.santepubliquefrance.fr/maladies-ettraumatismes/traumatismes

[3] E. Krug, J. Mercy, L. Dahlberg, A. Zwi, World Report on Violence \& Health. Biomédica . 22 Suppl 2. 327-36 (2003).
[4] S. Stith, T. Liu, L. Davies, E. Boykin, M. Alder, J. Harris, A. Som, M. McPherson, D. J.E.M.E.G. Risk factors in child maltreatment: A meta-analytic review of the literature. Aggression and Violent Behavior. 14. 1329 (2009).

[5] T. Mulder, K. Kuiper, C. Put, G. Stams, M. Assink, Risk factors for child neglect: A meta-analytic review. Child Abuse Negl..77. 198-210 (2018).

[6] L. Hillier, B.A. Morrongiello, Age and gender differences in school-age children's appraisals of injury risk. J Pediatr Psychol, 123(4):229-238 (1998).

[7] T. Faelker, W. Pickett, R.J. Brison, Socioeconomic differences in childhood injury: a population based epidemiologic study in Ontario, Canada. Inj Prev, 16: 203-8 (2000).

[8] E. Alasya, The Incidence of Home Accidents Among Children Aged 1-6 Years and the Practices of Mothers Related With Home Accidents. Near East University, Institute of Health Science Nursing Program, Master's Thesis,Lefkoşa (2012).

[9] M. Balibey, S. Polat, İ. Ertem, U. Beyazova, F. Şahin, Factors leading to the accident Childhood Home Journal of Continuing Medical Education, 120, 3-89 (2011)

[10] T. Blakely, J. Atkinson, C. Kiro, A. Blaiklock, A. D'Souza, Child mortality, socioeconomic position, and one-parent families: independent associations and variation by age and cause of death, Int J Epidemiol, $132(3): 410-8,(2003)$

[11] D. Hamel, R. Pampalon, Traumatismes et défavorisation au Québec, INSPQ, p. 8 p, (2002).

[12] S. Farhat, A. S. Elgharbi, Accidents involontaires chez les enfants : Etat des lieux en Tunisie, Article du Journal Le temps (25 décembre 2008).

[13] A. Rekik, A. Zouari, A. Khaldi, A. Gargouri, A.Triki, Profil épidémiologique des accidents chez l'enfant tunisien. Rev. Pédiatr, (1989)

[14] X. Jiang, Y. Zhang, Y. Wang, B.Wang, Y. Xu, L. Shang, An analysis of 6215 hospitalized unintentional injuries among children aged 0-14 in northwest China. Accident. Anal.Prev. 42. 320-6 (2010).

[15] Y.H. Sun, I.T. Yu, T.W. Wong et al. Unintentional injuries at school in China-patterns and risk factors. Accident Anal. Prev. 38 (1), 208-214. (2006)

\footnotetext{
Corresponding author: toual26@yahoo.fr
} 